\title{
Design of a Compact Dual-Band Microstrip Antenna Enabled by Complementary Split Ring Resonators for X-Band Applications
}

\author{
Ehab K. I. Hamad ${ }^{1}$, Mohamed Z. M. Hamdalla ${ }^{2}$ \\ ${ }^{1}$ Electrical Engineering Department, Faculty of Engineering, Aswan University, Aswan 81542, Egypt \\ ${ }^{2}$ School of Computing and Engineering, University of Missouri-Kansas City, Kansas City, MO 64110, USA \\ e.hamad@aswu.edu.eg, mhamdalla@mail.umkc.edu
}

\begin{abstract}
In this paper, a design of highly effective dual-band microstrip antenna for X-band applications is developed. Dual-band response is obtained by etching four rectangular split ring resonator (RSRR) unit cells within the radiating element of a conventional patch initially designed to operate at $10 \mathrm{GHz}$. The proposed antenna is constructed on low lossy RT/duroid $5880(\varepsilon r=2.2, \tan \delta=0.0009)$ substrate of $20 \times 20 \mathrm{~mm}^{2}$ total area and $1.575 \mathrm{~mm}$ thickness. The antenna is tuned to operate at two resonant frequencies between 8 and $12 \mathrm{GHz}$, depending on the geometric specifications of the RSRR's. A parametric study of different numbers of unit cells etched on the radiating element is investigated and discussed comprehensively through this study. Realized gain of about 6.2 and $6.8 \mathrm{~dB}$ at 8.8 and $10 \mathrm{GHz}$ are attained. Consistent results are obtained between measurement and simulation results using 3D full-wave FEM-base simulator.
\end{abstract}

\section{Introduction}

The rapid development of wireless communications generates a great interest in low cost, lightweight and mostly Omni-directional radiation pattern planar antennas. Microstrip antennas are a good candidate for such applications for its additional advantages of compact size and ease of fabrication. Microstrip antennas can be utilized for different applications such as mobile communication systems, synthetic aperture radar (SAR), global positioning systems (GPS), microwave sensors, biomedical telemetry services, WLAN, missiles, etc. [1-3]. Conventional microstrip antennas also suffer from some limitations such as narrow bandwidth, low gain, and poor efficiency. These limitations have been overcome by modifying these antennas in several ways. Such an example is using one antenna for multiple applications at once [4-5]. This means that single antenna can be employed for two or more frequency bands. This trend attracts the researchers to design microstrip antennas for dual-band and multiband operations to satisfy the multi-band communication applications. Many methods have been established to obtain a suitable multi-band performance, including forming slots on the patch [6] and etching slots on the ground plane [4]. The improvement of metamaterial (MTM) technology provides a new choice for the multi-band antenna designs. As it is known, the split ring resonators (SRRs) and complementary split ring resonators (CSRRs) are the most used basic metamaterial unit-cells. By etching these unitcells on the radiating element or loading them on the ground plane, multi-band characteristics can be realized [7-8]. Metamaterial-based antennas are proposed to exhibit several advantages over conventional patches such as enhancing the gain, bandwidth or antenna size [9-10]. The design in [11] uses a metamaterial lens to take full advantage of the antenna gain. Also, planar metamaterials are used intensively to scale down the antenna size by using two different metamaterial unit cells to create three resonances by the same antenna, which accomplishes a reduction in the antenna size.

In this paper, a dual-band microstrip antenna loaded with rectangular split ring resonators is proposed for the fulfillment of the X-band applications requirements. The proposed antenna is designed to resonate at 9.5 and $10 \mathrm{GHz}$ with appropriate bandwidths at both frequencies. The proposed design has a relatively high gain of 6.18 and 6.81 $\mathrm{dB}$ at 8.8 and $10 \mathrm{GHz}$, respectively. Finite Element Method (FEM) based software (Ansoft HFSS 13) is used for the analysis of the suggested antenna and optimizing its geometrical parameters.

This paper is organized as follows; In Section 2, the paper introduces the design of the conventional microstrip antenna at the desired frequency. The design of the rectangular metamaterial unit cell that will be used for adding another resonance is introduced in Section 3. In Section 4, the steps of modifying the conventional patch antenna using MTM unit cells to utilize the dual-band characteristic are introduced. The fabricated design and the measured results are discussed in Section 5. Section 6 concludes the whole work presented in this paper.

\section{Antenna design}

A conventional microstrip antenna, shown in Figure 1(a), is originally designed to operate at a frequency of $10 \mathrm{GHz}$. The basic design equations of rectangular microstrip are used to determine the length $\left(L_{P}\right)$ and width $\left(W_{P}\right)$ of the patch for the single band antenna using the transmission line model [12]. The obtained length and width of the optimized patch are $11 \mathrm{~mm}$ and $8.8 \mathrm{~mm}$, respectively with a copper thickness of $35 \mu \mathrm{m}$. The antenna is printed on Rogers $\mathrm{RT} /$ duroid 5880 substrate $(\epsilon \mathrm{r}=2.2, \tan \delta=0.0009)$ with a thickness of $1.575 \mathrm{~mm}$. 


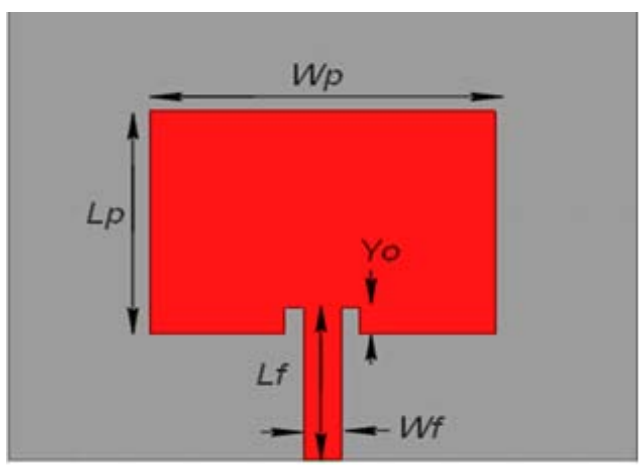

(a)

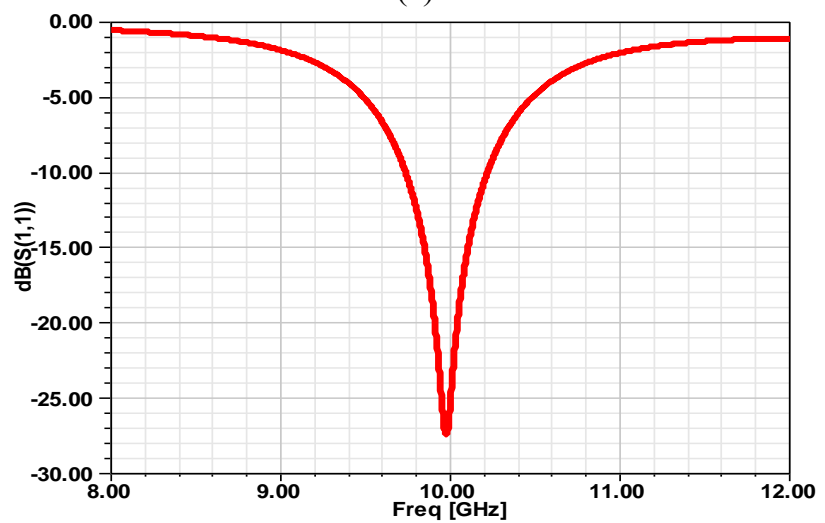

(b)

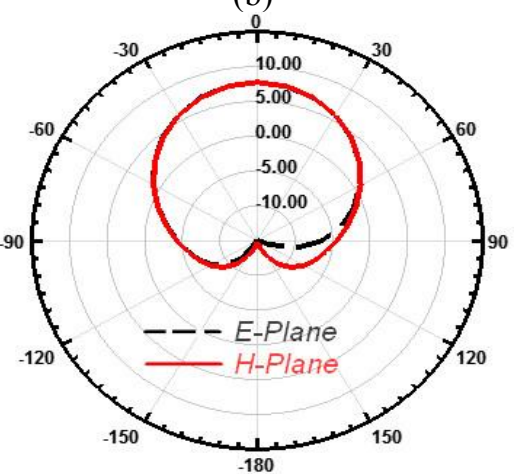

(c)

Figure 1: (a) Microstrip antenna operates at $10 \mathrm{GHz}$, (b) $\mathrm{S}_{11}$ of the conventional microstrip antenna operates at $10 \mathrm{GHz}$,

(c) Simulated E and $\mathrm{H}$-planes radiation pattern at $10 \mathrm{GHz}$.
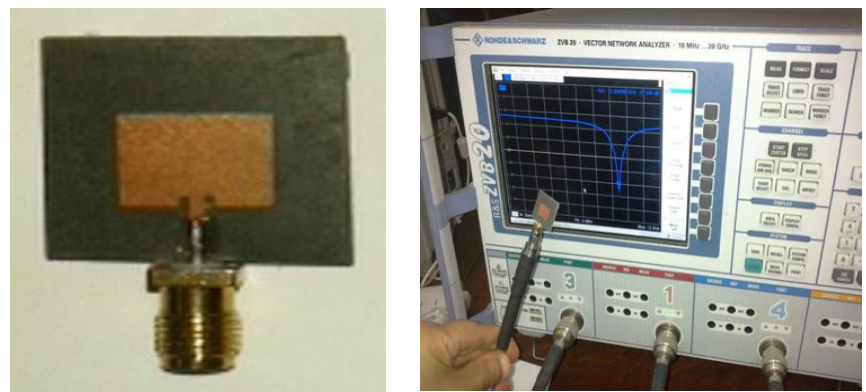

Figure 2: Fabricated microstrip antenna operates at $10 \mathrm{GHz}$ and its measurement setup.

The return loss of the designed antenna is shown in Figure $1(\mathrm{~b})$, where the antenna resonates at $10 \mathrm{GHz}$ with $-26 \mathrm{~dB}$ return loss. It has a peak realized gain of $7.2 \mathrm{~dB}$ at its resonance compared to the simulated antenna gain illustrated in Figure 1(c). These antenna performances are assumed to be a reference for comparison with the metamaterial-based antenna proposed in the coming sections. The reference antenna has been fabricated and measured to validate its behavior. Fig. 2 shows the measurement setup and the realized prototype of the designed antenna. All dimensions of the implemented antenna are as follow: $L p=8.8, W p=11, Y_{\mathrm{o}}=1, W_{\mathrm{o}}=0.6$, $L_{f}=6, W_{f}=1.2 \mathrm{~mm}$. The measured return loss of the fabricated conventional microstrip antenna is about $-24 \mathrm{~dB}$ at $10 \mathrm{GHz}$, which is quite close to that value of the modeled design, and the bandwidth is about $500 \mathrm{MHz}$.

\section{Metamaterial unit cell design}

The complementary split ring resonator (CSRR) unit cell is first designed by designing an SSR with similar dimensions to the CSRR dimensions and then replacing the metal by space and the space by metal in the split ring resonator as Babinet's principle states [13]. The resonator is designed to produce a resonant frequency at $10 \mathrm{GHz}$. According to the duality theorem, the frequency response of the SRR, which has negative permeability characteristics, is similar to the response of its complementary that has negative permittivity characteristics. The CSRR, seen in Fig. 3(a), has the following dimensions: $s=f=g=0.127 \mathrm{~mm}, L=W=3$ $\mathrm{mm}$. The simulated S-parameters are demonstrated in Fig. 3(b) which coincides with the results of the extracted relative permittivity shown in Fig. 3(c). The extracted relative permittivity of the metamaterial unit cell is negative of -1.2 at its resonance frequency $(10.2 \mathrm{GHz})$ as expected. The effective material parameters, effective permittivity and permeability, of the unit cell have been extracted from its corresponding scattering parameters based on the algorithm presented in [14]. The scattering parameters of this unit cell is extract using the boundaries illustrated in Fig. 4. Perfect magnetic conductor (PMC) boundary conditions are set on the left and right faces of the air box, and perfect electric conductor (PEC) boundary conditions are set on the top and bottom of the air box. The scattering parameters are calculated over a suitable frequency range in order to determine the resonance frequency and the effective parameters caused by that unit cell. The incident TEM wave propagates in the y-axis direction which will be later the same plane of the surface waves of the patch.

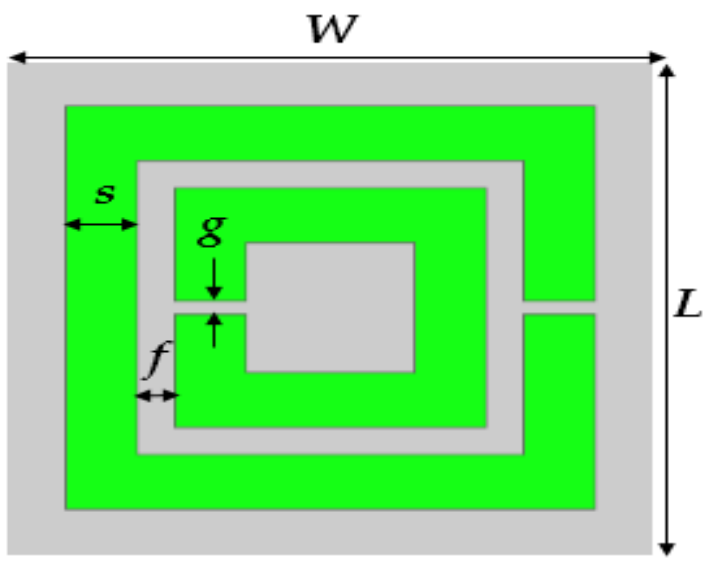

(a) 


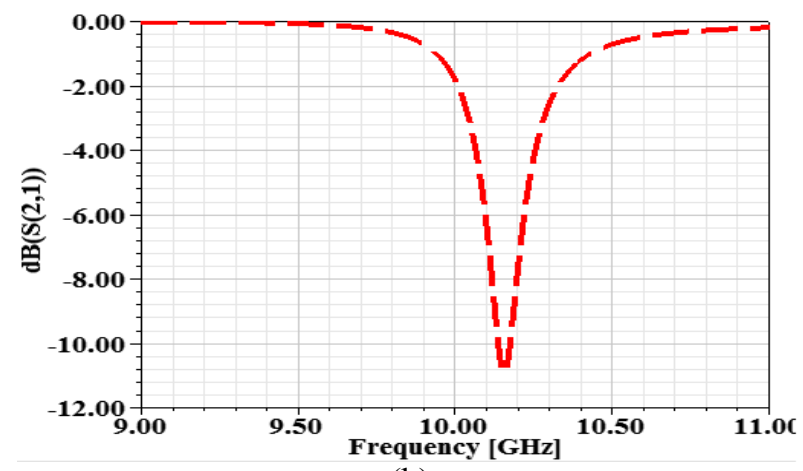

(b)

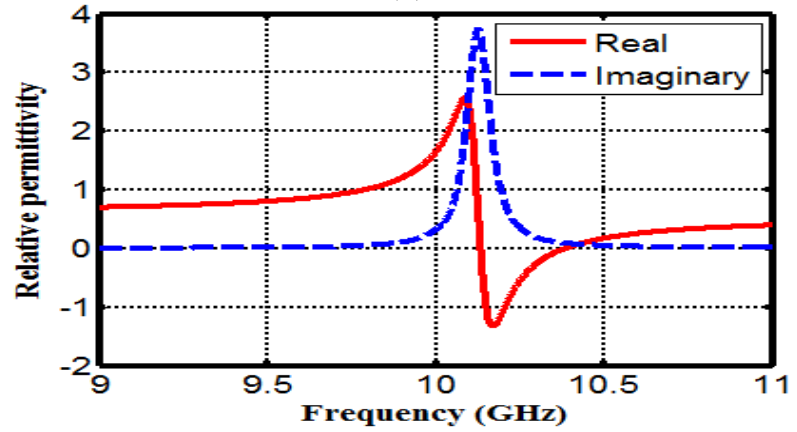

(c)

Figure 3: (a) Rectangular CSRR unit cell, (b) Simulated Sparameters of CSRR unit cell. (c) Extracted permittivity of the CSRR unit cell.
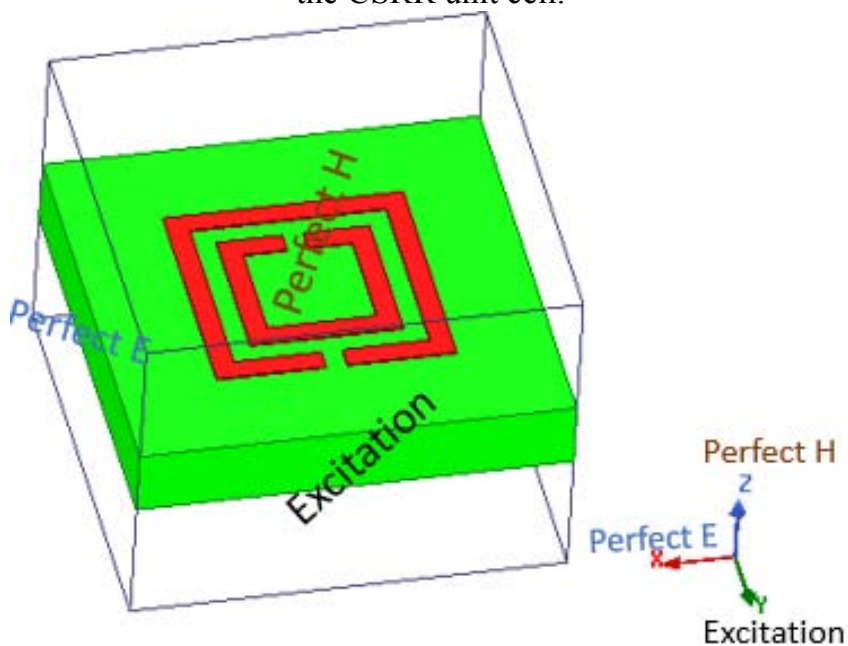

Figure 4: SRR unit cell setup for transmission analysis.

\section{Dual-Band Antenna Design}

The dual band behavior using metamaterial etched on the patch has been introduced at low frequency applications in details in [15-16]. The main idea is to etch a unit cell and excite this cell to add its resonance to the overall response of the antenna. As this work goal is to design an antenna at high frequencies, an intensive simulation to study the influence of etching CSRR unit cells within the patch is carried out using the 3D full-wave electromagnetic simulator (Ansoft HFSS 13). The inside of Fig. 5 illustrates the schematic diagram of the designed antenna with a single unit cell etched on the patch. The corresponding simulated return loss is depicted Fig. 5. The resonance of the patch is slightly shifted down to $9.45 \mathrm{GHz}$ and the resonance of the unit cell weakly appears at $10.17 \mathrm{GHz}$. The antenna realized gain at the resonance of the antenna $(9.45 \mathrm{GHz})$ is considerably high with about 7.16 and $7.51 \mathrm{~dB}$ at 9.45 and $10.17 \mathrm{GHz}$, respectively. These results are achieved after a comprehensive parametric study to determine the position of the unit cell within the patch based on the current distribution on the radiating element.

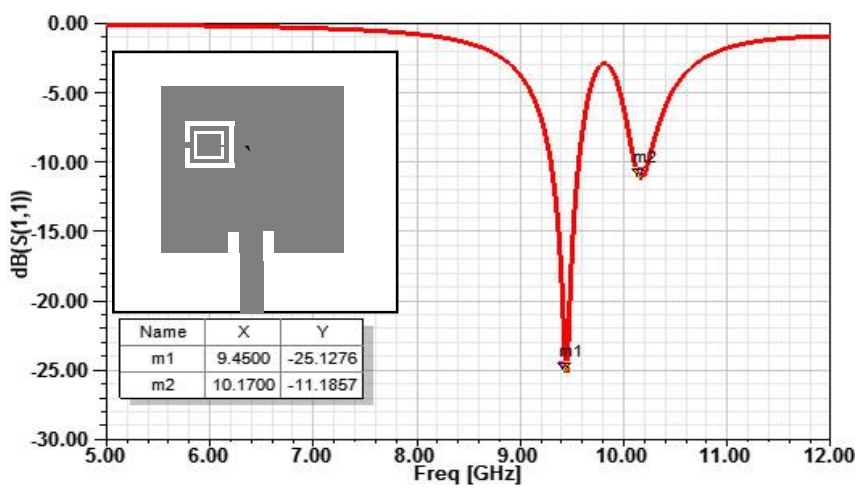

Figure 5: Dual-band antenna with single CSRR cell.

Figure 6 shows the designed antenna structure with additional unit cell etched on the patch horizontally aligned to the first one and the corresponding return loss. It could be noted that the return loss at the lower resonance is enhanced to reach $-35 \mathrm{~dB}$, while the upper resonance achieves poor performance. In contradiction, the realized gain at the lower resonance is lowered slightly to reach $7.02 \mathrm{~dB}$ while at the upper resonance increased to reach $7.38 \mathrm{~dB}$.

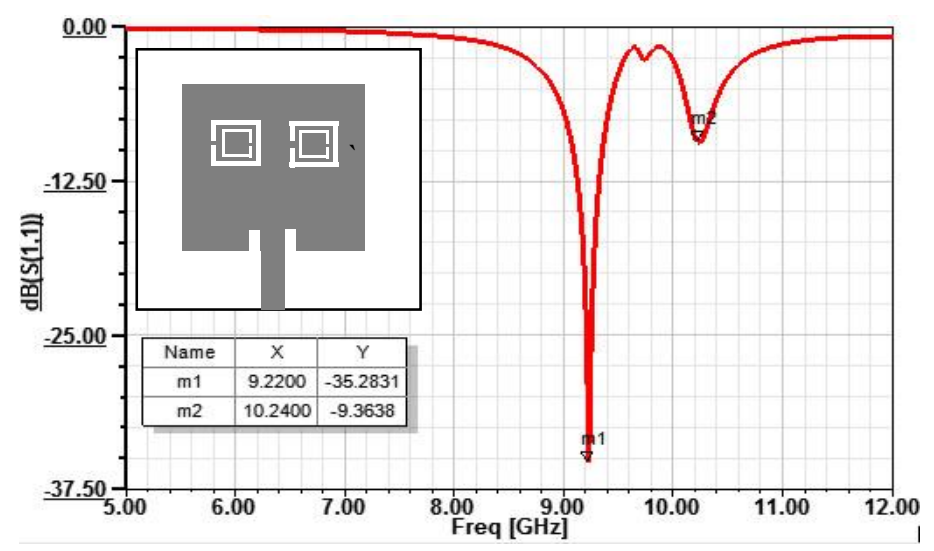

Figure 6: Dual-band antenna with two CSRR cells.

To enhance the return loss at the upper resonance that is produced by the MTM unit cell, a third CSRR unit cell is introduced and etched within the patch aligned vertically to the first one. The inside of Fig. 7 shows the designed antenna structure with three unit cells etched on the patch and the corresponding return loss is shown there also. It is clear that the return loss at the upper resonance is significantly enhanced; reaching $-18.5 \mathrm{~dB}$ and the lower resonance is shifted down to reach $9 \mathrm{GHz}$. The realized gain at both resonances is lowered to reach $6.95 \mathrm{~dB}$ at lower resonance while at the upper one reaches $7.08 \mathrm{~dB}$. 


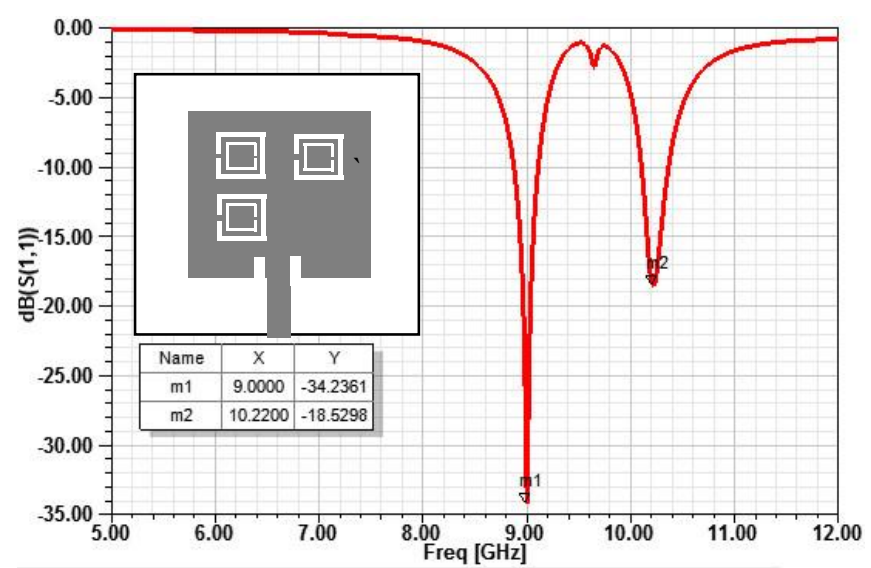

Figure 7: Dual-band antenna with three CSRR cell.

Finally, a fourth CSRR unit cell is created within the patch in the remaining space to further enhance the return loss at the upper resonance. The schematic structure of the patch with the four unit cells and its return loss response is illustrated in Fig. 8. This structure achieves the best performance among the different proposed structures. The lower resonance is to some extent shifted down but still within the desired range (X-band). The final peak realized gain is 6.77 and $7.2 \mathrm{~dB}$, at 8.83 and $10.3 \mathrm{GHz}$, respectively.

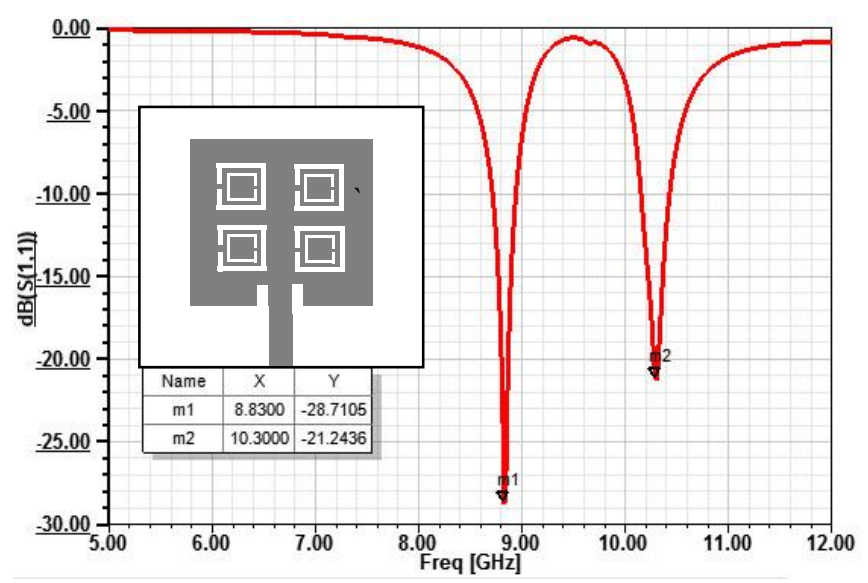

Figure 8: Dual-band antenna with four CSRR cells and its simulated return loss.

\section{FABRICATION AND MEASUREMENTS}

The proposed dual-band antenna is fabricated and tested for the purpose of validating the simulation results. The implemented prototype of the proposed dual-band antenna is shown in Fig. 9. Fig. 10 depicts the measured return loss compared to the simulated one. It may be observed that the fabricated model resonates at 8.8 and $10 \mathrm{GHz}$. The measurement results are fairly consistent with the simulated results. Low fabrication accuracy was responsible for the little nonconformity between simulations and measurements; mostly at the upper resonant frequency. Fig. 11 illuminates the standing wave ratio, which is less than 2 at both resonances. Table 1 shows a comparison between the proposed microstrip antenna results with and without integrating the MTM unit cells.

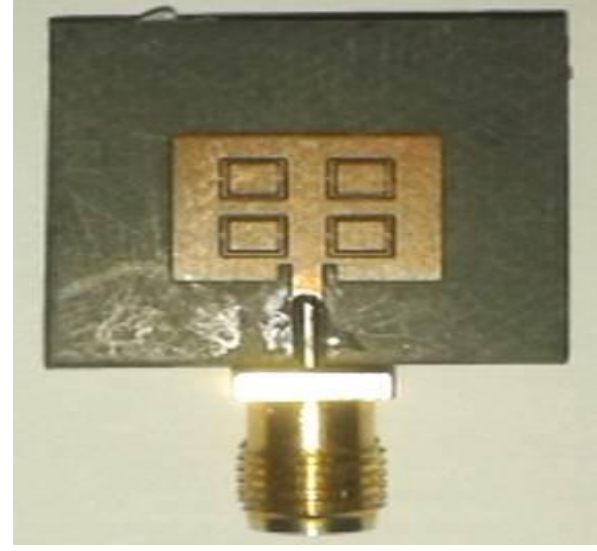

Figure 9: Fabricated antenna with four CSRR unit cells.

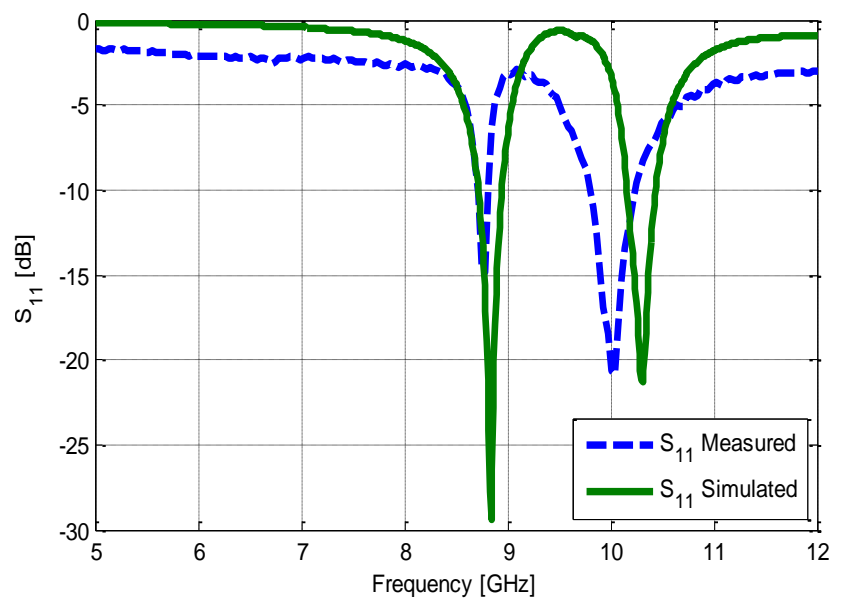

Figure 10: Measured and simulated $S_{11}$ of the proposed antenna.

Table 1: Performance comparison between designed antennas with and without MTM.

\begin{tabular}{cccc}
\hline \hline & Without MTM & \multicolumn{2}{l}{ With four CSRRs } \\
\hline Resonant & 10 & 10.3 & 8.82 \\
Frequency & -20 & -28 & -28 \\
S11 & 5.94 & 6.18 & 6.81 \\
Gain &
\end{tabular}

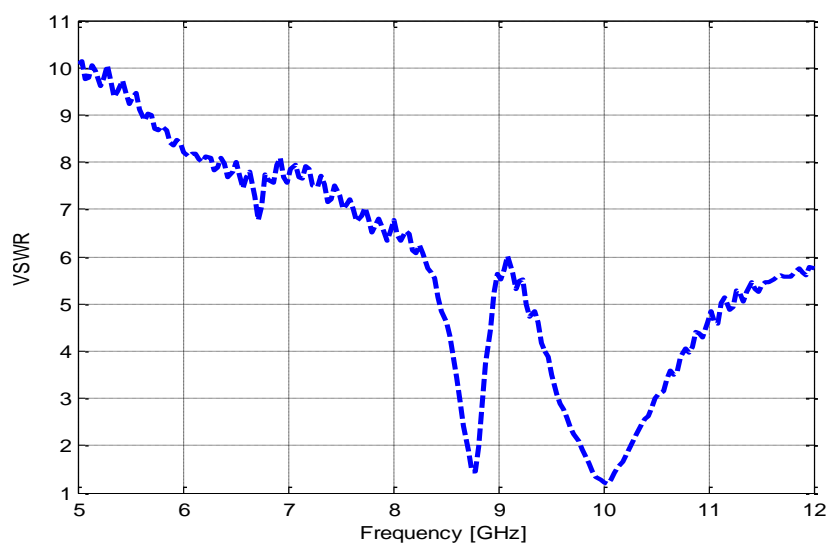

Figure 11: Measured SWR of the proposed antenna 


\section{Conclusions}

This paper proposes a very compact dual-band antenna constructed based on CSRR technique. The effects of various numbers of the MTM unit cells and its position within the radiating element are provided through $3 \mathrm{D}$ fullwave EM simulation model. The dimensions of the proposed antenna are $20 \times 20 \times 1.575 \mathrm{~mm}^{3}$. The antenna is printed on the low loss Rogers RT/duroid 5880 substrate of $\epsilon \mathrm{r}=2.2$. A relatively high gain of 6.18 and $6.81 \mathrm{~dB}$ for the two X-band resonant frequencies of 8.8 and $10 \mathrm{GHz}$ are obtained. Good and acceptable matching between the measured and simulated results have been achieved.

\section{Acknowledgments}

The authors would like to thank Yasmin Mohamed, Shereen Mohamed, Sara Alaaedeen, Alyaa Mahmoud, and Mohammed Salahedeen, at the Electronics and Comm. Dept., Arab Academy for Science, Aswan for their great help in fabricating and measuring the model.

\section{References}

[1] Miller, A.J., "Setting for Fixed-Cycle Traffic Signals", Operation Research Quarterly, Vol. 14, pp. 373-386, 1963.

[2] Amandeep K. S., Jagtar S. S., "Double U-Slotted Microstrip Rectangular Patch Antenna for GPS Applications," Int. Conf. on Electrical, Electronics, and Optimization Techniques (ICEEOT), 03-05 Mar 2016; Chennai, India, pp. 1569-1572.

[3] Ng K. K., Harita J., Safiza S., Gobi V., "Design and Development of Microstrip Antenna for C-Band Airborne Synthetic Aperture Radar (SAR) System," Asian Conference on Remote Sensing (ACRS), 12-16 November 2007, Kuala Lumpur, Malaysia.

[4] Adnan S., Mustafa H. B. U., "An Implantable Microstrip Antenna Design for Biomedical Telemetry," Int. Conference on Electronics, Computer and Computation (ICECCO), 7-9 Nov. 2013, Ankara, Turkey.

[5] Merih P., "Dual Broadband Antenna with Compact Double Ring Radiators for IEEE $802.11 \mathrm{ac} / \mathrm{b} / \mathrm{g} / \mathrm{n}$ WLAN Communication Applications," Turk J Elec Eng \& Comp Sci, 2017; 25: 1326 -1333.

[6] Ahmed F. D., Mahmoud A. A., and Hadia M. E., "New Configuration for Multiband Ultra Compact Gap Resonator Based D-CRLH," 3rd Middle East Conferences on Antennas and Propagation (MECAP), September 2016, Bairut, Lebanon.

[7] M. A. Bassiuny, E. K. I. Hamad, W. A. Aly and M. Z. M. Hamdallah, "Dual-band microstrip antenna for WiMAX applications using complementary split ring resonators," 2016 33rd National Radio Science Conference (NRSC), Aswan, 2016, pp. 57-63.

[8] Xie Y. H. , Zhu C., Li L., Liang C. H., "A Novel DualBand Metamaterial Antenna Based on Complementary
Split Ring Resonators," Microw. Opt. Technol. Lett., Vol. 54, 2012, pp. 1007-1009.

[9] Ehab K. I. Hamad, Mohamed Z. M. Hamdalla, "Design of Miniaturized and High Isolation Metamaterial-Based MIMO Antenna for Mobile Terminals" Journal of Engineering Sciences, Assiut University, Vol. 45, No. 6, November 2017, pp. 764-773.

[10]Li Y. S., Yu W. H., "A Miniaturized Triple Band Monopole Antenna for WLAN and WiMAX Applications, "Int. J. Antennas Propag., Vol. 2015; 2015, pp. 1-12.

[11]E. K. I. Hamad, W. A. E. Ali, M. Z. M. Hamdalla and M. A. Bassiuny, "High gain triple band microstrip antenna based on metamaterial super lens for wireless communication applications," 2018 International Conference on Innovative Trends in Computer Engineering (ITCE), Aswan, 2018, pp. 197-204.

[12] Balanis C.A. Antenna Theory: Analysis and Design, 3rd Edition, John Wiley \& Sons, USA 2005, pp. 811-876.

[13]Falcone F., Lopetegi T., Laso M.A.G., Baena J.D., Bonache J., Beruete M., Marqués R., Martín F., Sorolla M., "Babinet Principle Applied to the Design of Metasurfaces and Metamaterials," Phys. Rev. Lett. Vol. 93, No. 19, November 2004.

[14]Ziolkowski R. W., "Design, Fabrication, and Testing of Double Negative Metamaterials," IEEE Transactions on Antennas and Propagation, Vol. 51, No. 7, July 2003, pp. 1516-1529.

[15] Noelia Ortiz, Francisco Falcone, and Mario Sorolla "Gain Improvement of Dual Band Antenna Based on Complementary Rectangular Split-Ring Resonator," ISRN Communications and Networking, 9 pages, Volume 2012.

[16] J. Malik and M. V. Kartikeyan, "Metamaterial Inspired Patch Antenna with L-Shape Slot Loaded Ground Plane for Dual Band (WiMAX/WLAN) Applications," Progress In Electromagnetics Research Letters, Vol. 31, 35-43, 2012. 